\title{
As deputadas federais eleitas por São Paulo, em 2018, são feministas ou antifeministas?
}

\author{
Isadora Gonzaga Postingher
}

Vania Sandeleia Vaz da Silva ${ }^{2}$

Resumo: As lutas feministas pelos direitos civis, políticos e sociais para as mulheres foram responsáveis por conquistas, tais como a possibilidade de se candidatar, votar e exercer cargos eletivos no legislativo e executivo de vários países considerados democráticos, principalmente no Ocidente. As reivindicações por igualdade geraram políticas afirmativas que implicaram a obrigação - por parte dos partidos políticos - de apresentarem candidatas mulheres nos pleitos para os legislativos. Entretanto, o fato de uma candidata ser "mulher" não garante que terá uma atuação feminista - na defesa de pautas históricas e fundamentais para as mulheres - caso seja eleita. Inclusive, algumas candidatas podem se valer de sua postura antifeminista para se elegerem. Isso pode ser ilustrado por meio da análise de algumas postagens no Twitter, nos discursos de quatro deputadas federais, eleitas pelo estado de São Paulo, nas eleições de 2018: Joice Hasselmann (PSL), Tabata Amaral (PDT), Kátia Sastre (PL) e Sâmia Bomfim (PSOL). Os posicionamentos das deputadas eleitas permitem afirmar que poderiam ser classificadas como feministas ou antifeministas? Para responder essa questão, escolhemos caracterizar o que seria um discurso feminista ou antifeminista por meio da elaboração de dois "tipos ideais" no sentido weberiano - enfatizando posições altamente polarizadas - de modo a permitir localizar os discursos das deputadas dentro de um espectro ideológico que inicia em um extremo antifeminismo e termina em um extremo feminismo, passando por duas posições intermediárias: antifeminismo brando e feminismo brando.

Palavras-chave: Mulheres na política. Deputadas federais. Feminismo. Antifeminismo.

Graduada em Ciências Sociais (Unioeste, Campus de Toledo). E-mail: isadora_gp@hotmail.com.

2 Graduada em Ciências Sociais (UFPR), Mestre e Doutora em Ciência Política (USP), professora no curso de Ciências Sociais na Unioeste, Campus de Toledo. E-mail: vaniasandeleiavazdasilva@yahoo.com 


\title{
Are the federal deputies elected by São Paulo in 2018 feminist or anti-feminist?
}

\begin{abstract}
Feminist struggles for civil, political and social rights for women were responsible for achievements such as the possibility of running for, voting for, and holding elected positions in the legislature and executive in several countries considered democratic, especially in the West. The necessity for equality, generated affirmative policies that implied the obligation - on the part of the political parties - to present female candidates in the legislative elections. However, the fact that a candidate is a "woman" does not guarantee that she will have a feminist role - in defense of historical and fundamental guidelines for women - if she is elected. Even some candidates can take advantage of their anti-feminist stance to get elected. This can be illustrated by analyzing some posts on Twitter of the speeches of four federal deputies elected by the state of São Paulo in the state of 2018: Joice Hasselmann (PSL); Tabata Amaral (PDT); Kátia Sastre (PL); and Sâmia Bomfim (PSOL). Do the discurs of elected deputies permit that they will be classified as feminist or anti-feminist? To answer this question we chose to characterize what would be a feminist or anti-feminist discourse through the preparation of two "ideal types" in the Weberian sense - emphasizing highly polarized positions - in order to allow us to locate the speeches of the deputies within an ideological spectrum that begins in an extreme anti-feminism and ends in an extreme feminism, passing through two intermediate positions: soft anti-feminism and soft feminism.
\end{abstract}

Keywords: Women in politics. Federal deputies. Feminism. Antifeminism. 


\section{Introdução ${ }^{3}$}

A participação da mulher na política institucional pode ser pensada como uma conquista do movimento feminista, dado que os direitos políticos - votar, candidatar-se para cargos do executivo e do legislativo - só foram adquiridos devido às lutas de diversos movimentos feministas nos últimos séculos. Por isso é comum pensar que as "mulheres" que participam da política seriam "feministas" ou estariam ao menos envolvidas com as lutas pelos direitos das "mulheres". Porém, como mostraremos, nem todas defendem pautas que são favoráveis às questões historicamente defendidas pelas feministas, tais como a descriminalização do aborto, a licença maternidade, além de pautas sobre o combate à violência de gênero em todas as suas manifestações, incluindo a máxima que é o feminicídio, cujo agravamento recente exige participação política das mulheres para seu combate, por meio de políticas públicas mais efetivas.

Poderia parecer que a eleição de quatro deputadas federais por São Paulo, em 2018, representaria uma grande conquista para as feministas, que há tanto tempo buscam participar mais ativamente da política institucional. Contudo, caberia discutir em que medida o fato de uma candidata ser "mulher" significa que ela irá defender os interesses das mulheres, tal como são definidos pelos movimentos feministas. As deputadas federais eleitas, cujas postagens no Twitter serão analisadas, são as seguintes: Joice Hasselmann (PSL), Tabata Amaral (PDT), Policial Kátia Sastre (PL) e Sâmia Bomfim (PSOL). Será que as postagens estariam mais alinhadas com o feminismo ou com a atual reação antifeminista? Para responder essa questão, escolhemos caracterizar o que seria um discurso feminista ou antifeminista por meio da elaboração de "tipos ideais" no sentido weberiano - enfatizando posições polarizadas - de modo a permitir localizar os discursos das deputadas dentro de um espectro ideológico que varia de um extremo feminista até outro antifeminista.

O "tipo ideal" é uma ferramenta de análise que busca generalizar características típicas de um fenômeno social e, assim, permite explicitar o quanto os casos reais se aproximam ou afastam do modelo. Foram selecionadas algumas características que seriam indispensáveis ao tipo ideal de discurso "feminista" e também de um que estaria alinhado com uma reação "antifeminista" ou de crítica severa ao feminismo. Os dois tipos ideais foram criados para facilitar a identificação de posicionamentos mais polarizados, servindo como um instrumento de análise para os discursos difundidos nas mídias sociais, por pessoas envolvidas diretamente com a política institucional, como as deputadas escolhidas para serem estudadas neste texto.

Posteriormente, foram colhidas e analisadas algumas das postagens das deputadas no Twitter, que incluíam algumas palavras-chave, como: (1) mulheres, (2) igualdade, (3) feminismo, (4) antifeminismo, (5) aborto e (6) moral. Depois de acessar a página de cada uma das deputadas, foi realizada uma "busca avançada" com essas palavras. A escolha das palavras foi baseada no que parecia indicar o posicionamento. Por exemplo, a busca pela palavra-chave "mulheres" resultou em postagens que se referiam, de alguma forma, ao tema; "igualdade" poderia remeter a pautas feministas; "feminismo", "antifeminismo", "aborto" e "moral" permitiram filtrar postagens específicas. Listamos quais seriam as principais ideias vinculadas ao "feminismo" e ao "antifeminismo" para

\footnotetext{
O artigo constitui um desdobramento e aprofundamento do Trabalho de Conclusão de Curso que foi defendido por Isadora Gonzaga Postingher e orientado por Vania Sandeleia Vaz da Silva. Para o artigo, buscamos aprimorar a análise e sintetizar a metodologia e as descobertas que podem auxiliar outras pesquisas do mesmo tipo. Contudo, cabe ressaltar que se trata de um trabalho que tem seus limites por ser fruto de uma pesquisa inicial.
}

4 Ela foi eleita pelo Partido da República (PR), que depois mudou o nome para Partido Liberal (PL). 
elaborarmos um sistema de "pontos" que permitisse realizar uma "contagem" capaz de gerar um resultado que localizasse as deputadas no espectro criado com quatro categorias.

As categorias criadas foram: (1) Extremo antifeminista (-28 a -15), (2) Antifeminismo brando (-14 a -1), (3) Feminismo brando (1 a 14) e (4) Extremo feminista (15 a 28). Os números se referem à quantidade de "pautas" que levantamos em relação ao feminismo e ao antifeminismo. A cada defesa de uma pauta feminista, foi atribuído um ponto positivo (+1) e a cada defesa de pautas antifeministas, um ponto negativo (-1). Assim, ao final, quanto maior a pontuação mais próxima do feminismo ideal (extremo) se localizava a deputada e quanto menor a pontuação mais próxima do antifeminismo ideal (extremo). Ao somar os elementos que caracterizam seus discursos, foi possível localizar cada uma dentro de um espectro ideológico que vai de um extremo feminista até o seu oposto, o atual discurso ou reação antifeminista que espelha os principais preconceitos misóginos e patriarcais denunciados pelas feministas, desde o início do movimento. Por meio das categorias, foi possível localizar cada deputada de acordo com seus posicionamentos.

Compreendemos que se trata de uma metodologia que se baseia em uma simplificação, pois os posicionamentos "reais" são mais complexos e não seriam facilmente classificáveis só pelo uso que as deputadas fazem das "palavras". Contudo, considerando o papel que as mídias sociais desempenham na política atualmente, o uso e a repetição de "palavras" reforçam posicionamentos bem polarizados. Além disso, por meio da análise dos conteúdos e pontuação em termos de defesa ou ataque aos direitos das mulheres, foi possível representar, em um gráfico, como as deputadas estão posicionadas em relação às pautas historicamente defendidas pelos feminismos. Sabemos que a realidade é mais complexa, mas esperamos contribuir com um início de discussão a respeito da possibilidade de verificar, com certa acuidade, se uma parlamentar está alinhada com o feminismo ou está ampliando o alcance da reação antifeminista.

\section{Feminismo e antifeminismo}

Para falar sobre mulheres, sua história, reivindicações e conquistas, é necessário compreender o movimento feminista e, atualmente, também o antifeminismo, que mais se caracteriza como uma "reação" do que como um movimento, de acordo com as suas próprias participantes. Podemos começar com a definição da brasileira Céli Regina Jardim Pinto (2010), que afirma que o feminismo é um movimento que tem o objetivo de libertar a mulher, reivindicando espaço para ela na vida pública, na educação, no trabalho, bem como a autonomia para tomar decisões referentes à sua vida e ao seu corpo. Esse movimento se originou após a Revolução Francesa, momento de grandes conquistas de direitos políticos e jurídicos que foram concedidos apenas aos homens.

O feminismo ocidental pode ser pensado a partir de um enquadramento em três ondas e cada onda ou cada momento histórico tinha reivindicações diferentes. A primeira "onda" começou em torno do final do século XIX. As mulheres lutavam por direitos políticos, sociais e econômicos, como votar, ser eleita, trabalhar, estudar, ter direito a propriedade e a herança. As mulheres inglesas conhecidas como suffragettes organizaram-se primeiramente na Inglaterra, na busca de obterem seu direito ao voto. Em consequência disso, muitas delas foram presas e o direito ao voto feminino só foi concedido em 1918. É importante ressaltar que essas feministas olhavam apenas para suas semelhantes, da mesma classe e cor, esquecendo-se de que as negras também eram mulheres, mas com pautas diferentes daquelas defendidas pelas mulheres "brancas" da elite, da classe média e mesmo das trabalhadoras. 
Sojourner Truth (1851), negra, feminista e escrava apontou o esquecimento das mulheres negras em seu discurso Ain't I a woman?, criticando o machismo e a exclusão das negras enquanto sujeitos do feminismo:

Aquele homem diz que as mulheres precisam ser ajudadas a entrar em carruagens, erguidas para passar sobre valas e receber os melhores lugares em todas as partes. Ninguém nunca me ajudou a entrar em carruagens, a passar por cima de poças de lama nem me deu qualquer bom lugar! E eu não sou uma mulher? Olhem pra mim! Olhem pro meu braço! Tenho arado e plantado e recolhido em celeiros, e nenhum homem poderia me liderar! E eu não sou uma mulher? Posso trabalhar tanto quanto e comer tanto quanto um homem - quando consigo o que comer - e aguentar o chicote também! E eu não sou uma mulher? Dei à luz treze filhos e vi a grande maioria ser vendida para a escravidão, e quando eu chorei com minha dor de mãe, ninguém, exceto Jesus, me ouviu! E eu não sou uma mulher? (TRUTH, 1851 apud, BIROLI; MIGUEL, 2014, p.15).

A segunda onda surgiu depois da Segunda Guerra Mundial e, nesse caso, as mulheres reivindicavam o direito ao próprio corpo, ao prazer e lutavam contra o patriarcado. Foi um período de discussão sobre direitos reprodutivos e sexuais, quando se inicia o debate sobre a diferença entre "sexo" e "gênero". Cabe lembrar que a filósofa Simone de Beauvoir é apontada como uma precursora dessa discussão porque apresenta o argumento que permite separar o sexo do gênero quando, no segundo volume de seu livro chamado $O$ segundo sexo, afirma que "não se nasce mulher, torna-se mulher" (BEAUVOIR, 1967:9). Ser "mulher" passou a ser pensado como algo "social" e não determinado pela biologia. A palavra "homem" também foi problematizada nesse período, pois era utilizada para definir o ser humano em geral, representando algo neutro. Isso acabou incomodando o movimento feminista.

Assim, o que o movimento reivindicava o fazia em nome da "Mulher", e não do "Homem", mostrando que o "homem universal" não incluía as questões que eram específicas da "mulher". Como exemplos podemos citar: o direito de "ter filhos quando quiser, se quiser" -, a luta contra a violência doméstica, a reivindicação de que as tarefas do lar deveriam ser divididas, enfim, era em nome da "diferença", em relação ao "homem" - aqui pensado como ser universal, masculino, que a categoria "Mulher", era reivindicada. (PEDRO, 2005, p. 80).

Por fim, a terceira onda foi iniciada retomando o debate entre sexo e gênero, porém sob outro prisma. Judith Butler (2003) questionou o conceito de "mulheres" como sujeitos do feminismo, isto é, para ela, tanto o sexo como o gênero eram produtos sociais. Criticou também o modelo binário de classificação (homem/mulher). Além disso, a interseccionalidade foi debatida "novamente" nesse período, quer dizer, o cruzamento entre categorias gera especificidades nas opressões que cada mulher sofre, dependendo de sua classe social, religião, gênero, cor, nacionalidade e mesmo orientação sexual.

Hoje é importante entender que existem os feminismos, no plural, pois o feminismo no singular não estava bastando para definir o conjunto de reivindicações, que são diferentes por causa da interseccionalidade: mulheres com condições de vida diferentes sentiam a opressão e subordinação de maneiras diferentes. Porém todas as pessoas que se definiam como mulheres queriam entender o porquê, em diversas sociedades, eram submetidas aos homens. "Todo este debate fez ver que não havia a 'mulher', mas sim as mais diversas 'mulheres', e que aquilo que formava a pauta de reivindicações de umas, não necessariamente formaria a pauta de outras" (PEDRO, 2005, p.82). 
Atualmente podemos perceber que o feminismo continua se expandindo, mas também se subdividindo entre feminismo negro, lésbico, liberal, entre muitas outras especificidades. Podemos também observar que, ainda hoje, as principais lutas e reivindicações englobam a grande maioria e que já eram demandas desde a segunda onda.

Constatamos que algumas correntes do movimento consideram problemático o fato de que, por meio da Internet, a perspectiva que tem ganhado maior visibilidade é um tipo de feminismo liberal, que corrobora o sistema capitalista, como afirmam as autoras feministas marxistas Cinzia Arruzza, Tithi Bhattacharya e Nancy Fraser (2019), responsáveis também pela organização da Greve Internacional das Mulheres:

[...] esse feminismo propõe uma visão de igualdade baseada no mercado, que se harmoniza perfeitamente com o entusiasmo corporativo vigente pela "diversidade". Embora condene a "discriminação" e defenda a "liberdade de escolha", o feminismo liberal se recusa firmemente a tratar das restrições socioeconômicas que tornam a liberdade e o empoderamento impossíveis para uma ampla maioria de mulheres. Seu verdadeiro objetivo não é a igualdade, mas meritocracia. (ARRUZZA; BHATTAACHARYA; FRASER, 2019, p.37).

Depois de compreender as "ondas" existentes dentro do feminismo, podemos começar a falar sobre o antifeminismo, que não se autodeclara como um movimento, e sim, como uma "reação", de acordo com Sara Winter, ex-feminista e participante do Femen no Brasil, em uma entrevista concedida para a revista Época, Calcagno (2018). É importante ressaltar que essa corrente de ideias sempre existiu, porém parece perder ou ganhar forças em determinados momentos da história. Um episódio marcante e não muito distante foi o ocorrido em 1980, quando houve um contra-ataque às conquistas das mulheres, que ficou conhecido como blacklash. Assim diz Susan Faludi (1991):

Mas se o medo e a intolerância em relação ao feminismo são uma espécie de condição viral da nossa cultura, isto não quer dizer que eles sempre se manifestem em sua fase aguda; os sintomas permanecem e periodicamente voltam à tona. E são justamente estes episódios de reincidência, como o que estamos vivendo agora, que podemos definir como “backlash”, um contra-ataque para impedir o progresso da mulher. (FALUDI, 1991, p. 18).

A autora, que é jornalista, mostra como a imprensa e o cinema da época estiveram presentes, articulando notícias para deslegitimar os direitos conquistados pelas mulheres até aquele momento, afirmando que eles traziam infelicidade e que a justificativa para os descontentamentos era o excesso de igualdade e liberdade. De acordo com essa perspectiva, as mulheres estavam surtando e ficando deprimidas por "falta de homens" ou de "filhos", ou seja, os jornais mostravam que a mulher estava se afastando de sua "essência" e "propósito" como fêmea, podendo ser essa a causa de toda a infelicidade. Porém, Faludi logo questiona e derruba tal argumento, trazendo dados de entrevistas feitas com as mulheres da época, em que elas mesmas afirmavam que não estavam descontentes devido à quantidade de liberdade, mas reclamavam dos salários mais baixos e da dupla jornada de trabalho, dentro e fora de casa.

Mas de que "igualdade" será que tantas autoridades estão falando? Se as mulheres americanas são tão iguais, por que representam, então, dois terços de todos os adultos pobres? Por que mais de $80 \%$ das mulheres que trabalham em tempo integral ganham menos de 20 mil dólares por ano, uma porcentagem quase duas vezes maior do que 
o índice masculino de pobreza? Por que é muito mais provável que elas morem em casebres, que não tenham direito a seguro-saúde e que na proporção de dois para um em relação aos homens não tenham aposentadoria alguma? Por que o salário médio de uma mulher continua tão inferior ao salário médio dos homens quanto há vinte anos? Por que qualquer mulher com formação universitária continua ganhando menos que um homem que tenha apenas o curso secundário (exatamente como acontecia nos anos 50) - e por que a mulher com curso secundário completo continua ganhando menos que um homem com o curso incompleto? Por que, com efeito, as mulheres americanas têm que enfrentar uma terrível defasagem salarial baseada na discriminação sexual adotada em todo o mundo desenvolvido? (FALUDI,1991, p.11)

Os discursos passados que ligavam o "feminismo" à ideia de não ser "feminina", como se isso fizesse perder a "essência" de ser mulher - como se houvesse uma essência -, e essa ideia de "guerra dos sexos" continuam presentes nos discursos antifeministas atuais. A desigualdade de gênero nunca foi "encoberta", e sim, o oposto. Sempre foi reafirmada e utilizada como uma justificativa biológica ou divina de que os dois sexos não eram iguais e, de acordo com Rachel Soihet (2005):

[...] a mulher que pensa, que fala, que escreve, a mulher que reclama, que se revolta é frustrada, feia e altamente perigosa. Realidade que há não longo tempo era endossada pelos médicos. Para a maioria deles, as mulheres normais eram pouco inteligentes e houve os que asseguraram que aquelas dotadas de forte inteligência e dotadas de erotismo intenso se revelavam extremamente perigosas, constituindo as criminosas natas. Eram incapazes da abnegação, da paciência, do altruísmo que caracterizam a maternidade, função primordial das mulheres a que estaria subordinada toda a organização biológica e psicológica daquelas normais. (SOIHET, 2005, p.599).

Atualmente, no Brasil, o antifeminismo tem ganhado força e o conservadorismo também, fato evidenciado pela eleição de Jair Bolsonaro como presidente da República em 2018, com pautas claramente conservadoras e baseadas em retrocessos com relação a direitos ligados ao gênero, à sexualidade e à diversidade afetiva e sexual. Deve ressaltar-se também que não são apenas pessoas com mais idade que compactuam com o antifeminismo. Alguns exemplos de mulheres mais novas são: Ana Caroline Campagnolo, eleita deputada estadual pelo Partido Social Liberal (PSL) de Santa Catarina e Sara Winter, ex-feminista e candidata em 2018 a deputada federal no Rio de Janeiro, pelo Democratas (DEM). O antifeminismo atual também não é característica apenas de um grupo social ou classe, ele engloba homens e mulheres, pessoas sem informação e até mesmo "intelectuais". Todas as deputadas tratadas neste trabalho possuem ensino superior e duas delas, que podem ser consideradas de "direita", são mais alinhadas com a reação antifeminista, mesmo não se intitulando ou usando essa palavra em nenhum de seus tweets, mas, quando consideramos seus conteúdos, fica claro seu repúdio ao movimento feminista e ligação com a esquerda.

Apesar de Joice Hasselmann ser contra pautas da agenda do movimento, como o aborto, é possível perceber algumas preocupações com alguns temas ligados às mulheres, como a maior participação na política, o combate contra a violência doméstica e o feminicídio. Joice defende a ideia de mulheres na política, porém "mulheres de verdade" - que são definidas do modo como seu grupo pensa os papéis de gênero. Ao mesmo tempo em que diz que tem um "compromisso" com as mulheres, também afirma que é contra políticas específicas e que estas dividem a sociedade, contradizendo-se. Anne Phillips (2001) conclui, em relação à dicotomia entre política de ideias e política de presença: 
A maior parte dos problemas, de fato, surge quando as duas são colocadas como opostos mutuamente excludentes: quando ideias são tratadas como totalmente separadas das pessoas que as conduzem; ou quando a atenção é centrada nas pessoas, sem que se considerem suas políticas e ideias. É na relação entre ideias e presença que nós podemos depositar nossas melhores esperanças de encontrar um sistema justo de representação, não numa oposição falsa entre uma e outra. (PHILLIPS, 2001, p. 289).

Por isso, é interessante analisar parte das postagens dessas deputadas para não incorrer no engano de concluir, por um lado, que basta ser mulher para merecer o voto das mulheres, nem, por outro, que apenas aquelas que se definem previamente como feministas é que estariam preocupadas com pautas relevantes para as mulheres em geral. Tais conclusões só podem surgir da análise do que elas efetivamente afirmam.

\section{Construção dos dois tipos ideais de discurso}

Para responder a pergunta deste trabalho, selecionamos os principais elementos que definem um discurso como feminista e como antifeminista para criarmos os dois tipos ideais extremos propostos - no sentido weberiano. Esse tipo ideal tem o objetivo de simplificação e generalização, portanto não é real, mas pode ser utilizado por um cientista social para analisar situações sociais reais. Para Weber (2004), o tipo ideal não é um tipo "exemplar" ou como as coisas deveriam ser, mas "trata-se da construção de relações que parecem suficientemente motivadas para a nossa imaginação e, consequentemente, 'objetivamente possíveis', e que parecem adequadas ao nosso saber nomológico" (2004, p.107). O tipo puro seria uma construção mental de algumas características do objeto de estudo com a finalidade de classificar esses objetos. Para Alberto Guerreiro Ramos (2006):

A noção de "tipo ideal" implica a admissão de que a ciência não é uma cópia da realidade, de que nosso conhecimento da realidade é, portanto, necessariamente limitado e imperfeito. "Tipos ideais" como feudalismo, capitalismo etc. jamais ocorrem no mundo concreto, com todos os característicos estabelecidos pelo cientista. São exageros propositados de situações concretas, cuja finalidade é servir para estimar o grau de pureza ou hibridês dos fatos. (RAMOS, 2006, p.269).

É importante lembrar novamente que pode acontecer que uma pessoa não afirme "todos" esses elementos no seu discurso (no caso, nas postagens) ou que defenda o conjunto de todas essas características, pois elas são "ideais" e não reais. Pode haver algumas contradições e incompreensões, que poderão ser percebidas ao longo do trabalho quanto à posição de cada deputada dentro do espectro. Uma que se diz contra o feminismo tem algumas pautas feministas e o contrário também ocorre. Faludi (1991) explica:

O backlash não é uma conspiração, com um conselho emanando ordens de uma sala de controle central, e as pessoas que se prestam aos seus fins muitas vezes nem estão conscientes dos seus papéis; algumas até se consideram feministas. Na maioria dos casos, as suas maquinações são disfarçadas e ocultas, impalpáveis e camaleônicas. E tampouco podemos dizer que todas as manifestações do backlash tenham o mesmo peso e o mesmo significado; muitas não passam de coisas efêmeras, geradas por uma máquina cultural que está continuamente à cata de "novos" ângulos. Considerados em conjunto, entretanto, todos estes códigos e bajulações, estes murmúrios e ameaças e mitos, levam irreversivelmente numa única direção: tentar mais uma vez prender a mulher aos seus papéis "aceitáveis" - seja como filhinha de papai ou criaturazinha romântica, seja como procriadora ativa ou passivo objeto sexual. (FALUDI, 1991, p. 21). 
Serão analisados fragmentos dos discursos das deputadas federais com o intuito de classificar suas posições ideológicas. Para que lado cada uma delas pende no espectro ideológico? É possível alguma deputada afirmar-se contra o feminismo e ter características e lutas feministas ou o contrário? Para responder a esses questionamentos, foram colhidos os principais elementos de um discurso feminista por meio das reivindicações de cada onda e foi feita uma lista com as características apresentadas no livro Feminismo para os 99\%: um manifesto, produzido por Cinzia Arruzza, Tithi Bhattacharya e Nancy Fraser (2019), que defendem a ideia de que o feminismo capaz de superar a atual crise, causada pelo capitalismo (neoliberal e imperialista), precisaria unir todas as lutas específicas em um combate generalizado contra o sistema. Para tanto, apresentam onze teses que foram consideradas para que os traços mais marcantes do feminismo estivessem presentes na pesquisa ${ }^{5}$. Algumas pautas do feminismo são desafiadas diretamente pelo antifeminismo e outras não são citadas ou debatidas. Então, vamos colocar lado a lado os dois tipos ideais, correlacionando o que é possível comparar e listando o que não está em correspondência, no Quadro 1. Mas foram consideradas também as bandeiras e pautas de outras versões do feminismo - como será visto a seguir - sobretudo porque o importante é notar em que medida as deputadas eleitas consideram as lutas históricas das mulheres por mais participação na política, bem como por direitos civis e sociais.

5 Apenas considerando os enunciados das teses já é possível perceber que se trata de um "feminismo extremo", pois, partindo-se da constatação de que "uma nova onda feminista está reinventando a greve" (tese 1), afirmam as autoras que "o feminismo liberal está falido" e por isso "é hora de superá-lo" (tese 2); então, partem para um ataque direto ao sistema econômico hegemônico, afirmando que "precisamos de um feminismo anticapitalista", que seja destinado ao " $99 \%$ " (tese 4), e defendem que "a opressão de gênero nas sociedades capitalistas está enraizada na subordinação social à produção que visa o lucro" (tese 5); e que "a violência de gênero assume muitas formas, sempre enredadas nas relações sociais capitalistas", daí que seja necessário "combater todas elas" (tese 6). Passam a explicar que "o capitalismo tenta regular a sexualidade", que precisa ser libertada (tese 7) e que "o capitalismo nasceu da violência racista e colonial" de modo que o feminismo precisa ser "antirracista e anti-imperialista" (tese 8) e que é preciso lutar para "reverter a destruição da Terra pelo capital", ou seja, ser "ecossocialista" (tese 9), e que "o capitalismo é incompatível com a verdadeira democracia e a paz", por isso o feminismo precisa ser internacionalista (tese 10). Por fim, convocam "todos os movimentos radicais a se unir em uma insurgência anticapitalista comum" (tese 11), portanto, percebe-se que se trata de um feminismo "extremo" (ARRUZZA; BHATTACHARYA e FRASER, 2019). 
Quadro 1 - "Tipos Ideais" de feminismo e antifeminismo

\section{FEMINISMO}

\section{ANTIFEMINISMO}

\begin{tabular}{|c|c|}
\hline Mulheres devem ter direito de votar & Contrárias ao voto feminino \\
\hline Mulheres devem ter direito de ser eleita & Contrárias à participação das mulheres na política \\
\hline Mulheres devem ter direito de trabalhar & Mulheres não devem trabalhar fora de casa \\
\hline Mulheres devem ter direito de estudar & Mulheres não devem ter direito ao estudo \\
\hline Mulheres devem ter direito a propriedade & Mulheres não devem ter direito a propriedade \\
\hline Mulheres devem ter direito a herança & Mulheres não devem ter direito a herança \\
\hline Mulheres devem ter direito ao próprio corpo & Mulheres não devem ter direito ao próprio corpo \\
\hline Mulheres devem ter direito ao prazer & Mulheres não devem ter direito ao prazer ${ }^{6}$ \\
\hline Mulheres devem ter direitos reprodutivos & Mulheres não devem ter direitos reprodutivos ${ }^{7}$ \\
\hline Mulheres devem ter direitos sexuais & Mulheres não devem ter direitos sexuais \\
\hline São contra o patriarcado & Favoráveis ao patriarcado ou negam sua existência \\
\hline Reconhecem diferenças entre sexo e gênero & Não reconhecem diferenças entre sexo e gênero \\
\hline Ou tanto sexo quanto gênero são sociais & Sexo e gênero são biológicos ${ }^{8}$ \\
\hline Crítica ao modelo binário: homem mulher & Aceita o modelo binário \\
\hline Afirmação da Interseccionalidade ${ }^{9}$ & Não "acredita" na Interseccionalidade ${ }^{10}$ \\
\hline Crítica ao essencialismo & Essencialistas (crenças naturais e imutáveis) \\
\hline Anticapitalista & Anticomunista \\
\hline Tenta libertar a sexualidade & Tenta regular a sexualidade \\
\hline Contra subordinação da reprodução social ${ }^{11}$ & Reprodução social é função natural da mulher \\
\hline O feminismo liberal precisa ser superado & Não engloba esta questão \\
\hline Antirracista & Não trata da questão racial \\
\hline Anti-imperialista & Não discute sobre imperialismo \\
\hline Ecossocialista & Não discute a questão ecológica \\
\hline Internacionalista & Internacionalista \\
\hline Não engloba esta questão & Em geral, apoiadoras de uma doutrina religiosa ${ }^{12}$ \\
\hline São revolucionárias & São conservadores \\
\hline Objetivam destruir clichês de gênero & Reafirmam papéis sexuais essencialistas (clichês) \\
\hline Se autodefine como "feminista" & Se autodefine como "antifeminista" \\
\hline
\end{tabular}

Fonte: Elaboração própria a partir da revisão bibliográfica sobre o tema.

6 Em geral, porque são favoráveis a uma “moral” rígida (ou religiosa) e aos "bons costumes" (ligados ao patriarcado).

Costumam ser contrários tanto ao aborto (legal), quanto aos métodos de contracepção, pois a aposta é feita no "controle" da sexualidade feminina por meio de regras de comportamento mais rígidas.

8 Por isso, afirmam que o que existe é uma "ideologia de gênero", que visa desnaturalizar o sexo biológico, e são contrários às discussões sobre gênero e diversidade sexual nas escolas.

9 A ideia de que raça, classe e gênero (e sexo) se intercruzam para gerarem opressões e desigualdades. Para uma explicação completa e bem estruturada, sugerimos a leitura do livro de Carla Akotirene, Interseccionalidade, da coleção Feminismos Plurais, publicado em 2018.

10 Afirmam que o que existe é uma "vitimização" - reclamações por parte de grupos que pensam que classe, raça, etnia, gênero entre outros atributos geram desigualdade social, cultural, política, promovendo marginalização e preconceitos.

11 Mostram que trabalhos envolvidos com o "cuidado" - com crianças, idosos, pessoas com alguma necessidade derivada de doenças, entre outros - recaem sobre as mulheres e não são remunerados - tais como os trabalhos domésticos de limpeza, de alimentação, entre outros.

12 Sobretudo católicos ou evangélicos no Brasil. 


\section{Biografia e análise das postagens das quatro deputadas federais}

O Twitter é uma rede social que serve como microblogging, pois permite que seus usuários compartilhem mensagens, pensamentos, ideias, opiniões, atualizações de seu dia-a-dia entre outras funções, em tempo real. Essas postagens são conhecidas como tweets, podendo conter até 280 caracteres. A escolha do Twitter como local de análise dos discursos das deputadas citadas neste trabalho surgiu do fato de que todas possuíam uma conta na plataforma e, também, pela facilidade de filtrar palavras específicas e ter acesso às postagens mais antigas, o que é difícil de fazer através de outras plataformas, como o Facebook (que foi apenas usado como fonte de pesquisa da biografia das candidatas). Foram escolhidas seis palavras-chave para realizarmos as buscas que permitiram analisar o posicionamento de cada deputada: (1) mulheres, (2) igualdade, (3) feminismo, (4) antifeminismo, (5) aborto e (6) moral. A palavra "antifeminismo" não foi usada por nenhuma deputada em nenhum tweet. Foram considerados todos os posts desde que cada uma iniciou sua conta na plataforma, por isso existe uma desigualdade na "quantidade" de postagens examinadas e isso está sendo considerado na análise. ${ }^{13}$

Tabela 1 - Contagem das palavras utilizadas pelas deputadas

\begin{tabular}{|l|c|c|c|c|c|c}
\multicolumn{1}{c|}{ Deputada } & Mulheres & Aborto & Moral & Igualdade & Feminismo $^{\mathbf{1 4}}$ & Total \\
\hline Joice Hasselmann & 102 & 31 & 23 & 9 & 3 & 168 \\
\hline Tabata Amaral & 51 & 0 & 0 & 6 & 0 & 57 \\
\hline Kátia Sastre & 4 & 0 & 2 & 0 & 0 & 6 \\
\hline Sâmia Bomfim & 59 & 58 & 18 & 13 & 35 & 183 \\
\hline \multicolumn{1}{c}{ Total } & $\mathbf{2 1 6}$ & $\mathbf{8 9}$ & $\mathbf{4 3}$ & $\mathbf{2 8}$ & $\mathbf{3 8}$ & $\mathbf{4 1 4}$ \\
\hline
\end{tabular}

Fonte: Elaboração das autoras com base nos dados da pesquisa.

A primeira deputada a ser analisada é Joice Hasselmann, jornalista, escritora, colunista política, palestrante e agora deputada federal do estado de São Paulo pelo PSL (2019-2023), partido do atual presidente da república, Jair Bolsonaro. Líder do partido no congresso, foi a mulher mais votada pelo estado de São Paulo, com 1.078.659 votos. No ranking geral, ficou em segundo lugar, atrás apenas de Eduardo Bolsonaro, um dos filhos do presidente, que obteve 1.843.715 votos. Segundo sua biografia, retirada de sua página do Facebook ${ }^{15}$, foi eleita em 2017 a "Principal Influenciadora Política do Brasil" por uma revista e também foi considerada uma das "personalidades mais influentes e notórias das redes sociais, no âmbito da temática política e econômica." Ela afirma que atua por meio de redes sociais, como Facebook, Youtube, Instagram e Twitter, postando vídeos, textos e fotos, comentando sobre política. Afirma que tem um alcance de 30 milhões de pessoas através dessas plataformas digitais. Apesar de se declarar contra o feminismo, não se autointitula "antifeminista", ficando claras algumas contradições, como ser a favor de mais mulheres na política, mas acreditar que

13 A respeito da quantidade de tweets de cada deputada, cabe ressaltar que algumas tinham muitos e outras poucos, o que foi considerado na análise. Tabata Amaral criou sua conta em maio de 2018 e possui apenas 1.665 tweets, já Joice Hasselman possui sua conta desde fevereiro de 2010 e tem 51.594 tweets. Acontece o mesmo entre Katia Sastre e Sâmia Bomfim. Katia criou sua conta em agosto de 2018 e possui apenas 325 tweets, já Sâmia possui conta desde maio de 2009 e tem 13.819 tweets. (Acesso em: 03 nov., 2019, às 8h56).

14 Observação: Não foram encontradas postagens sobre "antifeminismo".

15 Disponível em: https://www.facebook.com/joicehasselmann/. Acesso em: 07 ago. 2019. 
políticas específicas são "ruins" e dividem a população. Das seis palavras-chave escolhidas, utiliza todas, menos "antifeminismo". Foram considerados 168 tweets, incluindo as postagens referentes às seis palavras-chave utilizadas desde a criação de sua conta na plataforma online Twitter até a primeira semana de setembro de 2019.

Tabata Amaral do PDT foi a segunda mulher mais votada do estado e se intitula como centro-esquerda. Foi a primeira vez que concorreu a um cargo político e é uma das mais novas deputadas federais do estado de São Paulo. Formou-se em Ciência Política nos Estados Unidos, por meio de bolsas de estudo. Veio de uma família carente e, de acordo com sua biografia do Facebook ${ }^{16}$, voltou ao Brasil, pois queria lutar por um país com oportunidades iguais para todos. Foi fundadora da organização "Mapa da Educação" e do movimento político independente "Acredito". Afirma que sua bandeira é a renovação política e a maior preocupação é a educação. Um fato curioso é que Tabata, apesar de se considerar centro-esquerda, votou a favor da reforma da previdência, se posicionando contra seu partido (PDT) e causando revolta de muitos de seus eleitores. Parece ser feminista, pois aborda muitas questões, como direito das mulheres, violência e principalmente sobre a necessidade de maior ocupação na política. Porém não se afirma feminista e não utilizou nenhuma vez a palavra "feminismo". Tenta parecer "neutra" em seus tweets, evitando palavras "polêmicas", como "feminismo" e "aborto", porém aborda questões sobre mulheres negras e indígenas, mostrando seu conhecimento e sua preocupação com a interseccionalidade. Das seis palavras-chave escolhidas, a deputada utiliza apenas "mulheres" e "igualdade", que resultaram em 57 tweets, todos até o final do mês de agosto de 2019.

Kátia Sastre tem 42 anos - mais conhecida como "Policial Kátia Sastre" - foi a terceira deputada mais votada e eleita pela primeira vez. É policial, formada em arquitetura, pós-graduada em Engenharia de Segurança. Ficou conhecida em maio de 2018, quando um assaltante a abordou juntamente com outras mulheres e crianças, na porta da escola de sua filha, onde ela estava devido a uma comemoração de dia das mães. Ela reagiu ao assalto, atirando e matando o assaltante. Durante sua campanha eleitoral, usou o vídeo gravado pelas câmeras de segurança da escola, em que ela aparecia matando o homem e "salvando" as crianças e mães que estavam na frente da escola. Kátia é do Partido Liberal (PL), antigo Partido da República (PR), caracterizado como centro-direita. Por meio da biografia ${ }^{17}$ e das postagens, podemos perceber que a deputada não aparenta se interessar pelo feminismo, mas se preocupa com o estupro, que é uma questão de segurança da mulher. Sua abordagem para solucionar o problema é através de penas mais severas para os estupradores. Das seis palavras-chave escolhidas, Kátia tuitou as palavras "moral" e "mulheres", que constituem apenas 6 tweets no total até o final do mês de agosto de 2019.

Sâmia Bomfim, do PSOL, ficou em $8^{\circ}$ lugar no ranking geral e foi a $4^{a}$ mulher mais votada, ficando atrás de Joice Hasselmann, Tabata Amaral e a Policial Kátia Sastre. Sâmia não é estreante na política, pois já foi vereadora, diferente das outras três deputadas. Em sua biografia do Facebook ${ }^{18}$, conta que, além de suas ações em gabinete e projetos, também participou de manifestações com o povo, como o "Fora Temer" e \#Elenão. Em seu mandato, ela luta por pautas como educação, saúde, cultura, moradia, segurança alimentar, direito à cidade, direitos das mulheres, direitos LGBTs, direitos de negros e negras, e direitos da juventude. Também

16 Disponível em: https://www.facebook.com/tabataamaralSP/. Acesso em: 07 ago.2019.

17 Disponível em:<https://www.facebook.com/policialkatiasastre/>. Acesso em: 07/08/2019.

18 Disponível em:<https://www.facebook.com/samia.bomfim.psol/>. Acesso em: 07/08/2019. 
também faz "das redes sociais uma ferramenta de aproximação e participação". Ela intitula-se feminista, luta em defesa do legado de Marielle, defende os direitos das mulheres e diz que "levanta bandeiras que a maioria dos políticos não têm coragem de levantar." A deputada, ao contrário de Tabata, não tem "medo" de usar as palavras "feminismo", "aborto" e "legalização", mostrando claramente seu posicionamento político-ideológico. Trata também, muito claramente, sobre interseccionalidade, debatendo temas como feminismo negro e indígena. Das seis palavras-chave escolhidas, a deputada utiliza todas, menos "antifeminismo". Foram 183 tweets, incluindo todas ou quase todas as postagens referentes às seis palavras-chave usadas desde a criação de sua conta na plataforma online Twitter até a primeira semana de setembro de 2019.

\section{As quatro deputadas são feministas ou antifeministas?}

Para analisar os posicionamentos das deputadas com relação ao feminismo e ao antifeminismo, atribuímos um ponto positivo $(+1)$ para cada pauta feminista defendida e um ponto negativo (-1) para cada pauta ligada ao discurso antifeminista. Quando não foi possível definir o posicionamento - por meio da análise das postagens e do que é publicamente conhecido sobre a parlamentar - atribuímos "zero" (0) que significa "não aferível” na nossa análise.

Tabela 2 - Posicionamentos das deputadas quanto ao feminismo e ao antifeminismo

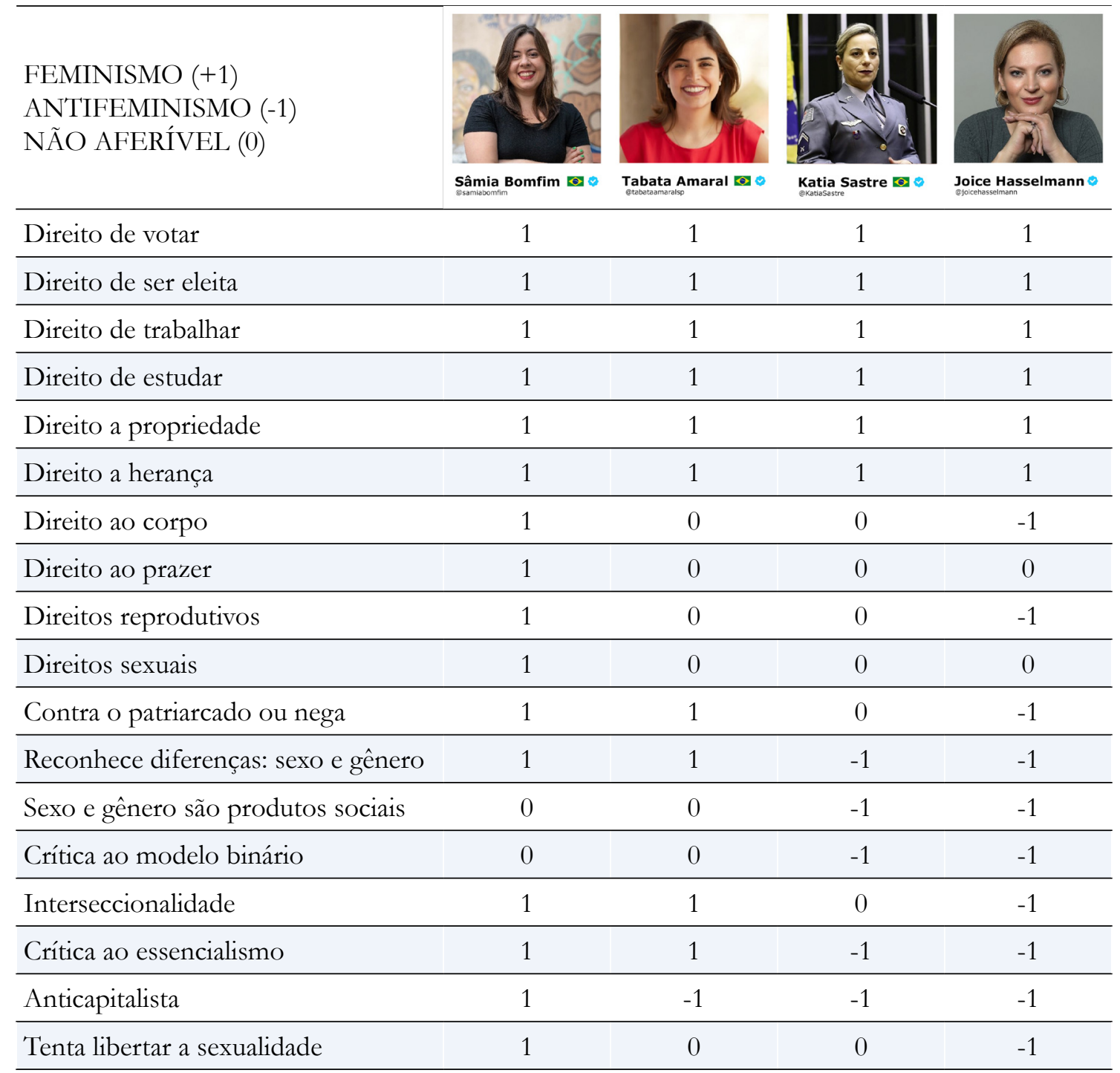


FEMINISMO (+1)

ANTIFEMINISMO (-1)

NÃO AFERÍVEL (0)
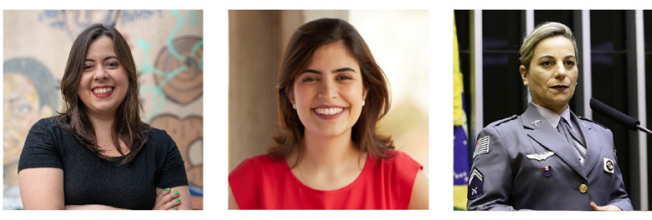

Sâmia Bomfim 지 હe

Tabata Amaral 이

Katia Sastre 서

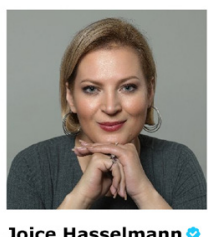

\begin{tabular}{lllll}
\hline Contra reprodução social não paga & 0 & 0 & 0 & 0 \\
\hline Feminismo liberal deve ser superado & 1 & 0 & 0 & 0 \\
\hline Antirracista & 1 & 1 & 0 & 0
\end{tabular}

\begin{tabular}{lllll}
\hline Anti-imperialista & 0 & 0 & 0 & 0 \\
\hline Ecossocialista & 0 & 0 & 0 & 0 \\
\hline Internacionalista & 1 & 1 & 0 & -1 \\
\hline
\end{tabular}

\begin{tabular}{lllll}
\hline Religiosas & 0 & 0 & -1 & -1 \\
\hline Revolucionárias & 1 & 0 & -1 & -1 \\
\hline Objetivam destruir clichês & 1 & 1 & -1 & -1 \\
\hline
\end{tabular}

Se autodefine como feminista/ antifeminista

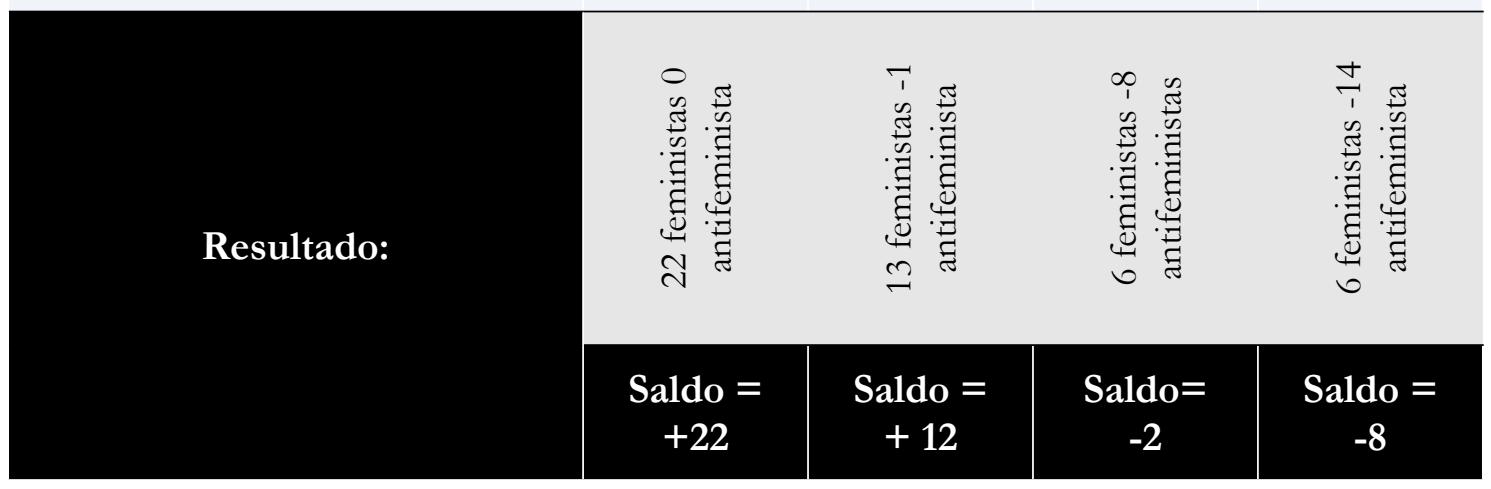

Fonte: Elaboração própria com base na pesquisa realizada ${ }^{19}$.

Podemos perceber - por meio do somatório dos pontos - que as categorias criadas permitiram notar que existem nuances importantes a serem consideradas e que o espectro ficou adequado como um meio de representar graficamente como estão posicionadas as deputadas estudadas. O resultado encontrado - duas na categoria de "antifeminismo brando"; uma no "feminismo brando" e uma no "extremo feminista" - pode ser bem percebido na visualização do "espectro" (gráfico 1), que permite afirmar que nenhuma das quatro deputadas pode ser considerada extremamente "antifeminista" pois nessa posição estariam apenas pessoas abertamente contrárias a todas as pautas feministas - cuja maioria está composta de "direitos" fundamentais para as mulheres, o que não aconteceu com nenhuma das deputadas estudadas.

19 A primeira versão desta tabela foi apresentada no Trabalho de Conclusão de curso de Isadora Gonzaga Postingher (orientado por Vania Sandeleia Vaz da Silva), sendo que para o artigo realizamos algumas correções. 
Gráfico 1 - Localização das deputadas no espectro Feminismo - Antifeminismo

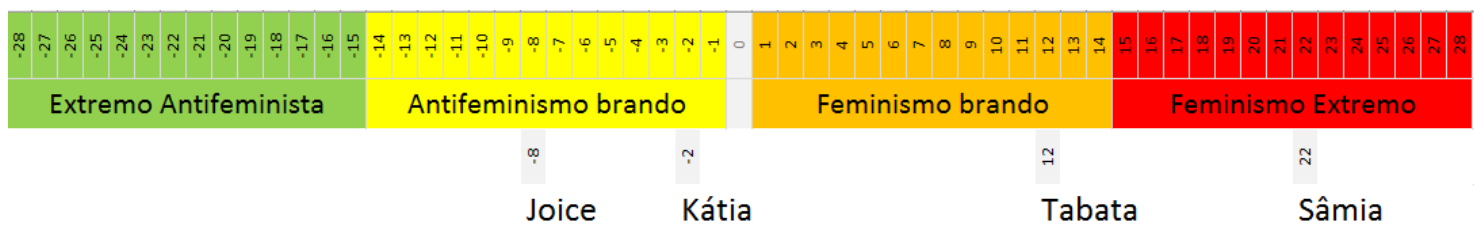

Fonte: Elaboração própria com base na pesquisa realizada ${ }^{20}$.

No caso do "antifeminismo brando", estão as parlamentares que, embora defendam várias das posições antifeministas, apoiam algumas pautas feministas - sobretudo relacionadas com a primeira onda. É o caso de Joice, que defende abertamente, pelo menos, 14 das posições antifeministas, mas também 6 das feministas. Nessa categoria, também está Kátia, que defende 8 posições antifeministas e 6 feministas. Já Tabata localiza-se como "feminismo brando", pois defende algumas das pautas feministas (13) e apenas uma antifeminista. Por fim, Sâmia é a única deputada que se encaixa em um tipo extremo de feminismo, pois defende quase todos os elementos que se caracterizam como feministas e nenhum antifeminista.

\section{Gráfico 2 - Representação em gráfico do somatório dos pontos de cada deputada}

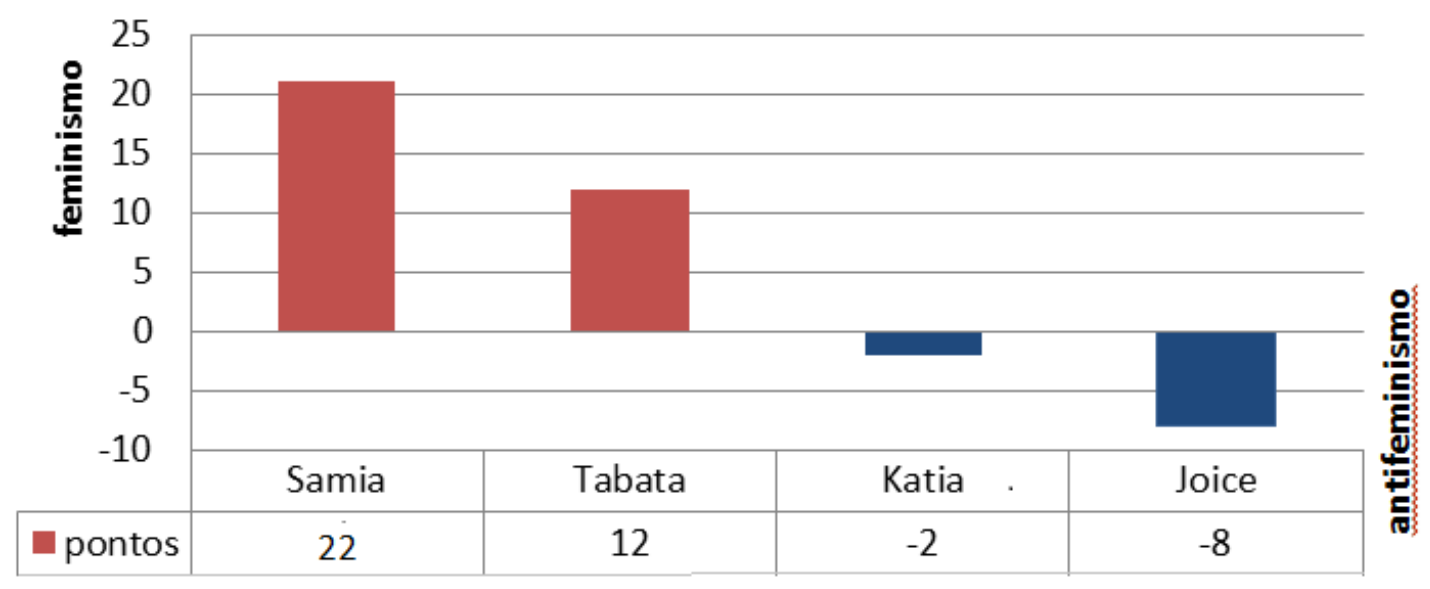

Fonte: Elaboração própria com base na pesquisa realizada

\section{Considerações finais}

Este trabalho teve o intuito de criar um "termômetro" do feminismo e do antifeminismo. Por meio dele, pode-se tornar possível a análise de alguns discursos, principalmente aqueles que são propagados nas redes sociais. Procuramos também mostrar que a simples política da presença pode não ser tão significativa, pois pode acontecer de alguns membros de grupos historicamente oprimidos (mulheres, por exemplo) promoverem políticas contrárias aos seus próprios grupos. Podemos tomar como exemplo as feministas liberais, que buscam ascensão de algumas mulheres e não de todas elas, ou até mesmo as mulheres antifeministas e conservadoras que querem participar da vida pública, porém questionam algumas reivindicações feministas, pois acreditam se tratarem de "vitimizações".

20 A primeira versão do espectro (apresentada no TCC) foi modificada, sobretudo pela inclusão do " 0 ”" (zero) como ponto neutro, em que estaria uma pessoa que não se posicionasse nem favorável nem contraria a quaisquer pautas. 
É interessante notar como cada deputada ficou posicionada no espectro: todas concordaram com pelo menos seis pautas do movimento feminista, por isso, nenhuma se caracterizou como antifeminista extrema, mas o contrário aconteceu. Como mostramos a deputada Sâmia Bomfim (PSOL) enquadra-se como feminista extrema, pois possui quase todas as características listadas como feministas e nenhuma antifeminista. Não podemos nos esquecer de que os resultados foram baseados apenas na análise de postagens filtradas e específicas, por isso não foi possível apurar e mensurar todos os posicionamentos de cada deputada em relação a todos os elementos. Desse modo, alguns desses elementos foram classificados como “não aferíveis". Entretanto, mesmo não podendo verificar todas as características, foi possível mostrar para qual lado cada deputada pende no espectro ideológico.

\section{Referências}

ARRUZZA, Cinzia; BHATTACHARYA, Tithi; FRASER, Nancy. Feminismo para os 99\%: um manifesto. São Paulo: Boitempo, 2019.

BEAUVOIR, Simone. O segundo sexo: A experiência vivida. Tradução de Sérgio Milliet. 2. ed. São Paulo: Difusão Europeia do Livro, 1967.

BIROLI, Flávia; MIGUEL, Luis Felipe. Feminismo e política: uma introdução. São Paulo: Boitempo, 2014.

BUTLER, Judith. Problemas de gênero: feminismo e subversão de identidade. Rio de Janeiro: Civilização Brasileira, 2003.

CALCAGNO, Victor. 'Feche as pernas': o que pregam os participantes do $1^{\circ}$ Congresso antifeminista do Brasil. Revista Época. 2018. Disponível em: https:/ / epoca.globo.com/feche-as-pernas-que-pregam-os-participantes-do-1-congresso-antifeminista-do-brasil-22964525. Acesso em: 07 ago. 2019.

FALUDI, Susan. Backlash: o contra-ataque na guerra não declarada contra as mulheres. Rio de Janeiro: Rocco, 1991.

PEDRO, Joana. Maria. Traduzindo o debate: o uso da categoria gênero na pesquisa histórica. Rev. História. São Paulo, v.24, n.1, p.77-98. 2005

PHILLIPS, Anne. De uma política de ideias a uma política de presença. Rev. Estud. Fem. Florianópolis, v .9, n.1, p. 268-290, 2001.

PINTO, Céli. Regina. Jardim. feminismo, história e poder. Rev. Sociol. Polit. Curitiba, v.18, n.36, p.15-23, 2010.

RAMOS, Alberto. Guerreiro. A sociologia de Max Weber. Rev. Do Serviço Público. Brasília, v. .57. n. 2, p. 267-282, 2006.

SOIHET, R. Zombaria como arma antifeminista: instrumento conservador entre libertários. Rev. Estud. Fem. Florianópolis, v.13, n.3, p.591-612., 2005.

WEBER, Max. A “objetividade” do conhecimento nas Ciências Sociais. In: COHN, Gabriel. (Org.). WEBER, Max. Sociologia. São Paulo: Ática, 2004. (Coleção Grandes Cientistas Sociais). 